\begin{tabular}{lcccr} 
T H E & A R C H I V E & O F & M E C H A N I C A L & E N G I N E E R I N G \\
\hline VOL. LX & 2013 & Number 1
\end{tabular}

10.2478/meceng-2013-0007

Key words: Fuzzy Arithmetic, Uncertainty, Multibody Systems, Robustness Analysis

NICO-PHILIPP WALZ* MICHAEL HANSS *

\title{
FUZZY ARITHMETICAL ANALYSIS OF MULTIBODY SYSTEMS WITH UNCERTAINTIES
}

The consideration of uncertainties in numerical simulation is generally reasonable and is often indicated in order to provide reliable results, and thus is gaining attraction in various fields of simulation technology. However, in multibody system analysis uncertainties have only been accounted for quite sporadically compared to other areas.

The term uncertainties is frequently associated with those of random nature, i.e. aleatory uncertainties, which are successfully handled by the use of probability theory. Actually, a considerable proportion of uncertainties incorporated into dynamical systems, in general, or multibody systems, in particular, is attributed to so-called epistemic uncertainties, which include, amongst others, uncertainties due to a lack of knowledge, due to subjectivity in numerical implementation, and due to simplification or idealization. Hence, for the modeling of epistemic uncertainties in multibody systems an appropriate theory is required, which still remains a challenging topic. Against this background, a methodology will be presented which allows for the inclusion of epistemic uncertainties in modeling and analysis of multibody systems. This approach is based on fuzzy arithmetic, a special field of fuzzy set theory, where the uncertain values of the model parameters are represented by socalled fuzzy numbers, reflecting in a rather intuitive and plausible way the blurred range of possible parameter values. As a result of this advanced modeling technique, more comprehensive system models can be derived which outperform the conventional, crisp-parameterized models by providing simulation results that reflect both the system dynamics and the effect of the uncertainties.

The methodology is illustrated by an exemplary application of multibody dynamics which reveals that advanced modeling and simulation techniques using some well-thought-out inclusion of the presumably limiting uncertainties can provide significant additional benefit.

* Institute of Engineering and Computational Mechanics, University of Stuttgart, Pfaffenwaldring 9, 70569 Stuttgart, Germany; E-mail: [nico.walz, michael.hanss]@itm.unistuttgart.de 


\section{Introduction}

In the modeling and simulation process of multibody systems (MBS), a preferably good knowledge of the model parameters is essential to obtain results that reflect the actual behavior of the real system. However, while models are becoming more detailed and more complex, the identification of the corresponding model parameters becomes more challenging in equal measure. The identified parameters can exhibit a high level of uncertainty, and exact values for their quantification can hardly be provided.

Moreover, despite the above-mentioned increasing attention to detailing in modeling, assumptions of idealization and simplification are required in order to achieve a mathematical description with an acceptable number of degrees of freedom. Hence, even apparently well-modeled MBS may exhibit inherent uncertainties due to deficiencies in modeling or imprecise data and imperfect knowledge. Uncertainties of this type are commonly classified as epistemic uncertainties [1], which additionally include absence of information, vagueness in parameter definition and subjectivity in numerical implementation. In this classification scheme the corresponding counterpart is denoted aleatory uncertainties, which are associated with natural variability or scatter.

The treatment of aleatory uncertainties is successfully accomplished by the use of probability theory and, in practice, mostly, by Monte Carlo methods or polynomial chaos methods. In contrast, the extended modeling involving epistemic uncertainties is still demanding from a methodological and computational view. In recent years, the concept of fuzzy set theory [2] is gaining attraction as a tool to model epistemic uncertainties. A special interdisciplinary methodology to comprehensive modeling and analysis of systems is presented which allows for the inclusion of uncertainties - in particular of those of epistemic type - from the very beginning of the modeling procedure. This approach is based on fuzzy arithmetic, a special field of the fuzzy set theory, which has gained practical relevance after the introduction of the Transformation Method [3].

In general, epistemic uncertainties are specified as parametric uncertainties by fuzzy numbers, which also includes model-structure uncertainties that are representable by parametric variations, i.e. the uncertainties manifest as uncertain model parameters and uncertain initial or boundary conditions. As a consequence, the use of a single configuration, with an estimated set of probable parameter values for the simulation of a model which is subjected to such uncertainties, cannot be considered representative of the whole spectrum of possible model configurations. A reliable assessment of the model is not possible with this restricted computational effort. Furthermore, the com- 
parison of the numerical simulations with data and results obtained from experimental testing may be difficult or even be rated unsatisfactory, due to unconsidered model uncertainties. Taking into account these uncertainties provides an advanced simulation output, wich ideally covers the measurement results.

The goal of this contribution is to show a general way of including epistemic uncertainties in MBS analysis. As a practical and illustrative example for showing some of the properties and possible post-processing steps of the fuzzy-based approach to comprehensive modeling and analysis of uncertain systems, a simple manipulator model will be investigated. In particular, epistemic uncertainties that arise from a lack of knowledge and from simplification during modeling are considered.

\section{Classification of Uncertainties}

Even though the forms in which uncertainty appears and manifests itself are numerous, the aforementioned categorization into two major classes, namely aleatory uncertainties and epistemic uncertainties, is widely acknowledged and proves to be well-suited [1]. Though other classifications are applicable in almost the same manner (e.g. [4]), this categorization is used throughout here. The following explanations shall elucidate the different concepts and their ranges of applicability.

\subsection{Aleatory Uncertainties}

Aleatory uncertainties result from natural variability or scatter in the physical properties of a system over time or space. They are random in nature and generally related to the uncertainty of the outcome of an event or experiment. Against this background, an efficient representation of aleatory uncertainties can be realized by the use of random numbers with their probability density functions derived from measurements and experimental data. As widely acknowledged in literature (e.g. [5], [6]), the most effective, versatile and predominantly used methods for the quantification of the propagation of the aleatory uncertainties through systems are based on probability theory as well as on Monte Carlo simulations and polynomial chaos methods for practical applications.

\subsection{Epistemic Uncertainties}

Epistemic uncertainties generally arise from insufficiency or even complete absence of knowledge, and they result, for example, in vagueness in 
parameter definition, subjectivity in numerical implementation, or simplification and idealization in the procedure of system modeling. Due to this significant and indisputably different character of epistemic uncertainties compared to aleatory uncertainties, probability theory may not be appropriate to effectively represent epistemic uncertainties [7]. Furthermore, practical data for a randomness-based quantification of the uncertainties are usually not available.

For these reasons, the alternative strategy of quantifying epistemic uncertainties by fuzzy numbers $[2,8]$ is pursued in this paper, and the propagation of the uncertainty through the system, i.e. the evaluation of the model with fuzzy-valued parameters, is performed by the use of fuzzy arithmetic [8,9]. In the first instance, the representation of epistemic uncertainties by ordinary intervals seems to be the most practical and straightforward approach if only worst-case bounds and no further information about a possible distribution within the interval is available. Apart from the fact that the evaluation of models with interval-valued parameters by the use of classical interval arithmetic proves to be rather problematic because of the dependency problem (also referred to as overestimation effect $[9,3]$ ), the sharp boundedness of the intervals acts quite contrary to the predominant human perception of quantifying imprecision. The somehow blurred bounds of fuzzy numbers, instead, comply much better with this view. Moreover, uncertainty propagation on the basis of only one particular set of intervals for the uncertain parameters will automatically raise the question about how the results of the propagation will change (in a qualitative and quantitative way) with the amount of initial uncertainty, i.e. with the lengths of the intervals assumed. Fuzzy numbers, which can be seen as a set of nested intervals ranging from a worst-case scenario in case of maximum uncertainty to a crisp nominal value in case of complete certainty (see Section 3), are perfectly suited to solve this limitation.

\section{Fuzzy Theoretical Concept}

As stated in the previous section, fuzzy set theory is well-suited for the description of epistemic uncertainties. An introduction to the theoretical foundations and the application to numerical analysis of dynamical models using fuzzy arithmetic is presented subsequently.

\subsection{Fuzzy Numbers}

A special application of the theory of fuzzy sets, which is rather different from the well-established use of fuzzy set theory in fuzzy control, is the 
numerical implementation of uncertain model parameters as fuzzy numbers [8]. Fuzzy numbers are defined as convex fuzzy sets over the universal set $\mathbb{R}$ with their membership functions $\mu(x) \in[0,1]$, where $\mu(x)=1$ is true only for one single value $x=\bar{x} \in \mathbb{R}$, the so-called center value or nominal value. For example, a fuzzy number $\widetilde{p}$ of triangular (linear) shape, expressed by the abbreviated notation [9]

$$
\widetilde{p}=\operatorname{tfn}\left(\bar{x}, \alpha_{1}, \alpha_{\mathrm{r}}\right),
$$

is defined by the membership function

$$
\mu_{\vec{p}}(x)=\left\{\begin{array}{lll}
0 & \text { for } & x \leq \bar{x}-\alpha_{1} \\
1+(x-\bar{x}) / \alpha_{1} & \text { for } & \bar{x}-\alpha_{1}<x<\bar{x} \\
1-(x-\bar{x}) / \alpha_{\mathrm{r}} & \text { for } & \bar{x} \leq x<\bar{x}+\alpha_{\mathrm{r}} \\
0 & \text { for } & x \geq \bar{x}+\alpha_{\mathrm{r}}
\end{array} .\right.
$$

However, any other shape of membership function may be selected if appropriate to quantify the uncertainty of a specific model parameter. The calculation with fuzzy numbers is referred to as fuzzy arithmetic and proves to be a non-trivial problem, especially with regard to the evaluation of large mathematical models with fuzzy-valued operands. For a profound description of the overall mathematical background of fuzzy variables in the framework of credibility theory, the reader is referred to the work of Liu $[10,11]$.

\subsection{Fuzzy Arithmetic - the Transformation Method}

The problem of incorporating uncertainties into complex numerical models has already been addressed in a number of publications, of which the vast majority is based on stochastic descriptions of the uncertainties. In that context, the early papers of Contreras [12] and Handa and Anderson [13], and the paper of Schuëller [5] are worthy of note. The problem of stochastic excitation is adressed in [14] using generalized polynomial chaos. A MBS containing uncertain rigid bodies is evaluated in [15] by random number and random matrix theory, applying the Monte Carlo method.

The alternative concept of using fuzzy descriptions of the uncertainties emerged more recently, and Rao and Sawyer [16] presented an approach for its incorporation into the finite element method. However, since that approach uses the conventional concept of standard fuzzy arithmetic, based on interval computation, it suffers considerably from the overestimation effect $[3,9]$, also referred to as the dependency problem or conservatism. With the objective of reducing this effect while maintaining the computational effort to an acceptable level, Moens and Vandepitte [17] presented a fuzzy finite 
element approach which is based on the application of special optimization strategies of an approximative character.

In [18] a flexible MBS using finite elements in a co-rotational frame is analyzed and computed using the vertex method, which has been introduced by Dong and Shah [19]. This method, however, is only applicable under certain monotonicity assumptions.

All of these approaches do not provide an easy way of generalization towards arbitrary systems including nonlinear systems such as MBSs and the solution in the time domain, if possible at all.

A related topic to computations with epistemic uncertainties in multibody dynamics is the notion of verified integration. However, it purely relies on interval arithmetic and is mainly concerned with bounding solutions due to rounding errors (e.g. [20. 21]). Because of overestimation effects from interval arithmetic, the solution bounds can become unstable, especially for longer integration timespans.

As a successful practical implementation of fuzzy arithmetic, which allows the evaluation of arbitrary systems with uncertain, fuzzy-valued model parameters, the Transformation Method [3] can be used. An example involving uncertainties of epistemic type in a mechanism is analyzed in [22]. Assuming the uncertain system to be characterized by $n$ fuzzy-valued model parameters $\widetilde{p}_{i}, i=1,2, \ldots, n$, the major steps of the method can briefly be described as follows:

In the first step, each fuzzy number $\widetilde{p}_{i}$ is discretized into a number of nested intervals $X_{i}^{(j)}=\left[a_{i}^{(j)}, b_{i}^{(j)}\right]$, assigned to the membership levels $\mu_{j}=j / m$, $j=0,1, \ldots, m$, that result from subdividing the possible range of membership equally spaced by $\Delta \mu=1 / m$ (Figure 1 ). In a second step, the input intervals $X_{i}^{(j)}, i=1,2, \ldots, n, j=0,1, \ldots, m$, are transformed to arrays $\widehat{X}_{i}^{(j)}$ that are obtained from the upper and lower interval bounds after the application of a well-defined combinatorial scheme $[3,9]$. Each of these arrays represents a specific sample of possible parameter combinations and serves as an input parameter set to the problem to be evaluated. As a result of the evaluation of the model for the input arrays $\widehat{X}_{i}^{(j)}$, output arrays $\widehat{Z}^{(j)}$ are obtained which are then retransformed to the output intervals $Z^{(j)}=\left[a^{(j)}, b^{(j)}\right]$ for each membership level $\mu_{j}$ and finally recomposed to the fuzzy-valued output $\widetilde{q}$ of the system.

In addition to the simulation part of the Transformation Method described above, the analysis part of the method can be used to quantify the influence of each fuzzy-valued input parameter $\widetilde{p}_{i}$ on the overall fuzziness of the model output $\widetilde{q}$. For these purposes, the standardized mean gain factors $\kappa_{i}$ and the normalized degrees of influence $\rho_{i}$ have been introduced [3,9], quantifying 
in an absolute and in a relative character, respectively, the effect of the uncertainty of the $i$ th model parameter $\widetilde{p}_{i}$ on the overall uncertainty of the model output $\widetilde{q}$.

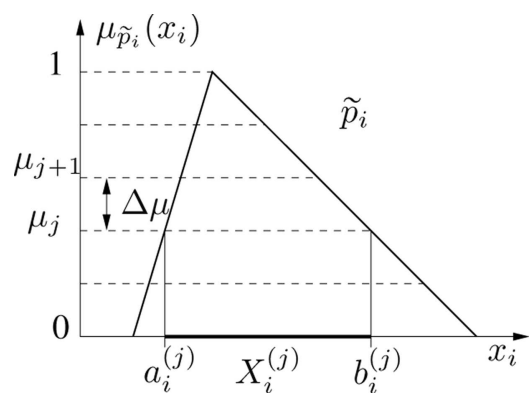

Fig. 1. Decomposition of a fuzzy number $\widetilde{p}_{i}$ into intervals $X_{i}^{(j)}, j=0,1, \ldots, m$

Among other advantages of the Transformation Method, its characteristic property of reducing fuzzy arithmetic to multiple crisp-number operations, i.e. deterministic computations, entails that the Transformation Method can be practically implemented into an existing simulation environment [9].

For this purpose, the program FAMOUS (Fuzzy Arithmetical Modeling Of Uncertain Systems) has been developed using the Matlab programming language and its object-oriented features. This facilitates a problem- and platform-independent implementation and enables a systematic and modularized way of interfacing with arbitrary simulation tools. With regard to the software structure, it is possible to distinguish between a preprocessing, a model evaluation and a postprocessing part of FAMOUS.

The preprocessing part is represented by the first two steps of the Transformation Method, namely the decomposition and the transformation step. Based on the information provided by the user, the fuzzy numbers or intervals corresponding to the input parameters are created, decomposed into the input intervals, and finally, transformed into the arrays necessary for the evaluation of the model.

To perform the evaluation of the model, FAMOUS can be coupled with any existing software. According to the input arrays resulting from the transformation step, FAMOUS passes the data to the evaluating process. In the last years, a previous version of FAMOUS was successfully used in combination with some of the most popular commercial FE software packages, such as ABAQUS and MSC.Nastran.

The postprocessing part of FAMOUS concludes the simulation of the uncertain system by the retransformation and the recomposition step. The results of the uncertainty propagation are the fuzzy-valued outputs of interest. In MBS analysis, difficulties may arise, e.g. when dependent output quantities 
shall be analyzed in different aspects, such as eliminating the independent variable or performing coordinate transformations. If these difficulties and the limitations caused thereby are not taken into account, overestimation of the uncertainty may be the consequence or - even worse - wrong results may follow. Also, underestimation may occur for systems with bifurcations in the given parameter range.

Finally, through the analysis module, it is possible to determine the proportions to which the $n$ fuzzy-valued parameters $\widetilde{p}_{i}$ contribute to the overall uncertainty of the outputs. In this case, the major results are the absolute and the relative measures of influence, $\kappa_{i}$ and $\rho_{i}$.

\subsection{Inverse Fuzzy Arithmetic - Uncertainty Identification and Model Validation}

Recently a further function module for the implementation of the inverse fuzzy arithmetic has been developed [23, 24]. The forward fuzzy arithmetical concept presented so far has been used to propagate known or assumed uncertainties of the model parameters through the system. Performing this analysis, it is implicitly assumed that the model is sufficiently appropriate to estimating the system behavior and that the specified fuzzy-valued parameters account for the residual model failure and uncertainty.

Inverse fuzzy arithmetic provides a way to perform an advanced parameter identification that explicitly takes into account epistemic uncertainties. In contrast to classical parameter identification procedures, the parameters are estimated as fuzzy numbers so that the resimulated output covers in a conservative sense the measured data available. Additionally, based on the results of the inverse fuzzy arithmetical approach, the quality or validity of the model can be quantified and rated, making use of the idea that the structurally most appropriate model needs a minimum uncertainty to include the measured outputs of the real system to be modeled. Using this methodology, one can also compare the quality of different models as demonstrated in [25].

\section{Multibody System Dynamics}

For the simulation of interconnected rigid bodies which perform large working motions, the multibody approach is frequently used. Applications using MBS formulations arise in a wide range of engineering problems, and therefore is a field of active research [26].

The derivation of the equations of motion by applying the Newton-Euler equations yields second order differential-algebraic equations (DAE). Those, in general, nonlinear equations can be transformed to a minimal form representation, i.e. to a set of ordinary differential equations, using generalized 
coordinates $\boldsymbol{y}$, thus eliminating the reaction forces which couple the ODE to the algebraic equations.

In the most general case, the parameter dependency might occur in the equations of motion as well as in the initial conditions on position and velocity level, $\boldsymbol{y}_{0}$ and $\dot{\boldsymbol{y}}_{0}$ respectively. In minimal form, the parametric system can then be written as follows

$$
\begin{aligned}
& \boldsymbol{M}(\boldsymbol{y} ; \widetilde{\boldsymbol{p}}) \ddot{\boldsymbol{y}}+\boldsymbol{k}(\boldsymbol{y}, \ddot{\boldsymbol{y}} ; \widetilde{\boldsymbol{p}})=\boldsymbol{q}(\boldsymbol{y}, \ddot{\boldsymbol{y}} ; \widetilde{\boldsymbol{p}}) \\
& \boldsymbol{y}(t=0 ; \widetilde{\boldsymbol{p}})=\boldsymbol{y}_{0}(\widetilde{\boldsymbol{p}}), \quad \dot{\boldsymbol{y}}(t=0 ; \widetilde{\boldsymbol{p}})=\dot{\boldsymbol{y}}_{0}(\widetilde{\boldsymbol{p}}) .
\end{aligned}
$$

Here, $\boldsymbol{M}$ denotes the minmal mass matrix, $\boldsymbol{k}$ is the vector of generalized centrifugal, Coriolis and gyroscopic forces, and $\boldsymbol{q}$ is the vector of the generalized applied forces. The fuzzy parameters are collected in the parameter vector $\widetilde{\boldsymbol{p}}$.

The process of forming the equations of motion can be accomplished by different schemes, using absolute or relative kinematics and using numerical or symbolic formulations. The solution procedure for obtaining the fuzzyvalued output requires the evaluation of the system Equation 3 at several perturbed states, i.e. at different points in the parameter space. Hence, for the purpose of analyzing parametric uncertainties, a symbolic formulation proves advantageous since the equations of motion only have to be set up once. Neweul-M ${ }^{2}$ represents a MBS simulation tool providing symbolic formulations [27].

\subsection{Elastic MBS and Model Order Reduction of Elastic Bodies}

In case elastic deformations of the bodies are not negligible, the large working motion has to be computed taking into account the influence of the elastic deflection. This can be achieved by the use of nonlinear finite element approaches where the ansatz functions approximating the deformation field are supplemented by parameters that account for slope or rotation. This approach is used, for instance, in the absolute nodal coordinate formulation or in the large rotation vector formulation [28, 29].

If the deflections are in the range of linear elasticity, the floating frame of reference approach provides an alternative and, in general, more efficient formulation. Here, the so-called reference frames are used to describe the large working motion. The elastic bodies are then attached to the reference frame, accounting for the deformation in the local coordinate system of the reference frame. Thus the position of a point on an elastic body is decomposed into the reference position, the position of the point relative to the reference frame, and the deflection. The system equations can still be written in the general form Equation 3, but $\boldsymbol{y}$ now contains additional elastic coordinates. 
The elastic bodies are usually modeled using the finite element technique for which a variety of software products are available, providing tools for a wide range of applications. The system dimension arising from this discretization is, in general, too big to be feasible for computation in the elastic MBS framework, but it is possible to represent the dynamic behavior of the system in the frequency range of interest by a rather small system which is obtainable using model reduction techniques. Besides the classical modal reduction techniques including component modes synthesis, modern reduction schemes based on balanced truncation or moment matching have gained significant attraction in recent years [30].

As long as the uncertainties to be considered are restricted to quantities attached to rigid bodies or joints, the propagation of those can be handled in the same manner as described before. So in this case, the inclusion of elastic bodies does not pose additional complexity in terms of the uncertainty quantification.

If uncertain parameters are, however, associated to structural parts, the situation becomes more complex. A possible solution is to compute a new elastic body for each sample point in the parameter space, i.e. to set up the system matrices of the FE model, perform a model reduction, and finally, derive the equations of motion of the newly build-up elastic MBS. This is an obviously time-consuming procedure that does not prove practical for complex systems.

A more effective, but also more demanding approach from a methodical point of view, is to perform the model reduction by taking into account the parametric dependency and retaining it in the resulting reduced model. This is known as parametric model order reduction (pMOR) and is a field of active research that has gained attraction just recently. The basic idea of most pMOR approaches is to obtain a representation of the full-order model by interpolating between several reduced-order models [31, 32]. Thus the reduced model still exhibits the parameter dependency, and the recalculation step of the elastic MBS equations is avoided in a symbolic framework again.

\subsection{Uncertainties in MBS}

Besides the well-studied aleatory uncertainties, such as variability of material properties and geometrical parameters due to irregularities in manufacturing or assembly, the epistemic uncertainties play an important role in MBS simulation. Those epistemic uncertainties can be classified on the basis of their origin and their nature in the following categories:

- Lack of knowledge or vagueness, e.g. a broad spectrum of possible operating conditions which are not known or only vaguely defined, such as initial conditions, applied loads, parameters of friction models etc. 
- Subjectivity in implementation, e.g. the selection of different methods of numerical evaluation by using different integration schemes, time steps, model order reduction methods and number of reduced basis vectors, etc.

- Deficiencies in modeling, e.g. idealization or simplification of models to ensure or facilitate the numerical evaluation, or idealized or simplified constitutive laws for material models, as done for composite materials, friction behavior, etc.

Usually, epistemic uncertainties of either of the three categories may occur in the modeling procedure of MBS. However, in the framework of comprehensive modeling, i.e. modeling both the system and potential uncertainties, these uncertainties can successfully be represented and quantified by fuzzy numbers, and the propagation of the uncertainties through the model can be evaluated by the use of the Transformation Method of fuzzy arithmetic.

\section{Example}

The following example shall illustrate the comprehensive modeling and analysis of a MBS by including uncertainties in terms of fuzzy-valued parameters. The system consists of a planar two-link manipulator with motors located at each of the two joints. A sketch of the model is shown in Figure 2. As illustrated, each arm has one degree of freedom, namely the angles $\theta_{1}$ and $\theta_{2}$ respectively, where motors apply torques $T_{1}$ and $T_{2}$ at the joints. Additionally, viscous and friction damping is present in the links and implemented using the Stribeck friction model. The damping moment $\phi_{i}$ at joint $i$ is given by

$$
\phi_{i}\left(\dot{\theta}_{i}\right)=d \dot{\theta}_{i}+\phi_{\mathrm{C}}\left(\dot{\theta}_{i} ; \mu_{\mathrm{C}}\right)+\left(\phi_{\mathrm{s}}\left(\dot{\theta}_{i} ; \mu_{\mathrm{C}}\right)-\phi_{\mathrm{C}}\left(\dot{\theta}_{i} ; \mu_{\mathrm{C}}\right)\right) \mathrm{e}^{-\left(\dot{\theta}_{i} / v_{\mathrm{S}}\right)^{2}},
$$

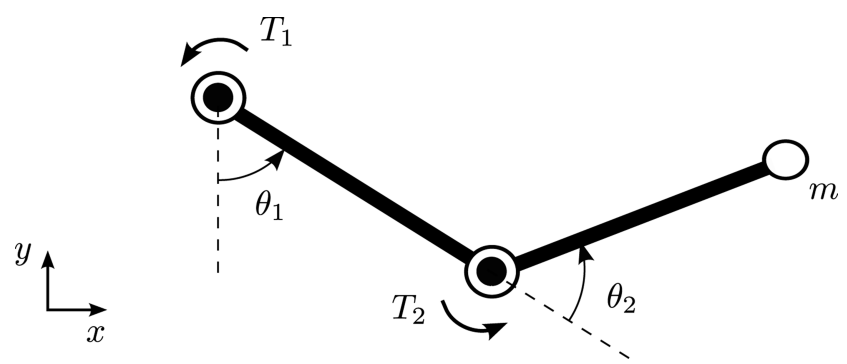

Fig. 2. Model of the two-link manipulator 
with the viscous damping coefficient $d$, the damping moment from Coulomb friction $\phi_{\mathrm{C}}$, which depends on the friction coefficent $\mu_{\mathrm{C}}$, and the damping moment from static friction $\phi_{\mathrm{s}}$ depending on the stiction coefficient $\mu_{\mathrm{s}} \cdot v_{\mathrm{S}}$ is called Stribeck velocity and is a scaling factor that influences the exponential decay from the static friction value to Coulomb friction with increasing angular velocity. At the tip of the second arm, a mass is attached, i.e. the end effector, which is intended to be driven along a certain trajectory. For this purpose, a feedforward control has been calculated based on the nominal model such that the actuated joints drive the end effector to the desired position.

The reference trajectory is given as the time-dependent position vector $\boldsymbol{x}_{\mathrm{ref}}=$ $\left[x(t)_{\mathrm{ref}}, y(t)_{\mathrm{ref}}\right]^{\mathrm{T}}$ of the end effector. Assuming that the model parameters are exactly known, the driven trajectory will only deviate from the intended trajectory to a small amount - mainly due to numerical imprecision.

Now, uncertainties in the model parameters shall be considered. In particular the mass of the end effector $m$ is not precisely known, which, for instance, might be due to the fact that different tool tips are mountable (lack of knowledge). Also, the friction damping, as described in Equation 4, is an enhanced, but still simplified model of friction. This can be seen as an uncertainty due to deficiencies in modelling, possibly including a lack of knowledge concerning the parameters. The uncertain parameters are all described by triangular fuzzy numbers, i.e. $\widetilde{p}_{i}=\operatorname{tfn}\left(\bar{x}_{i}, \alpha_{1, i}, \alpha_{\mathrm{r}, i}\right)$ as defined in Equation 2 in Section 3.1. The nominal values $\bar{x}_{i}$ and the worst-case deviations $\alpha_{1, i}$ and $\alpha_{\mathrm{r}, i}$ are listed in Table 1 .

Table 1.

Fuzzy parameter definitions

\begin{tabular}{|c|c|c|c|c|c|}
\hline & $\widetilde{p}_{1}:=\widetilde{d}$ & $\widetilde{p}_{2}:=\widetilde{\mu}_{\mathrm{s}}$ & $\widetilde{p}_{3}:=\widetilde{\mu}_{\mathrm{C}}$ & $\widetilde{p}_{4}:=\widetilde{v}_{\mathrm{S}}$ & $\widetilde{p}_{5}:=\widetilde{m}$ \\
\hline $\bar{x}_{i}$ & $0.05 \frac{\mathrm{kg}}{\mathrm{s}}$ & 0.4 & 0.3 & $0.1 \frac{\mathrm{rad}}{\mathrm{s}}$ & $1.0 \mathrm{~kg}$ \\
\hline$\alpha_{1, i} / \bar{x}_{i}$ & $2.5 \%$ & $2.5 \%$ & $2.5 \%$ & $2.5 \%$ & $1.0 \%$ \\
\hline$\alpha_{\mathrm{r}, i} / \bar{x}_{i}$ & $2.5 \%$ & $2.5 \%$ & $2.5 \%$ & $5.0 \%$ & $1.0 \%$ \\
\hline
\end{tabular}

Eventually, when these uncertainties are included into the analysis, the manipulator will no longer be able to exactly retrace the trajectory for all possible configurations, and significant deviations will occur instead. To quantify this effect, the system is simulated using the Transformation Method, as described above. The resulting fuzzy-valued trajectory is shown in Figure 3, where the end-effector motion is shown in $x$ and $y$ direction, and the membership value of solutions is indicated by their coloring. The black curve contained in the solution set is the solution of the nominal system which properly resembles the given trajectory. 


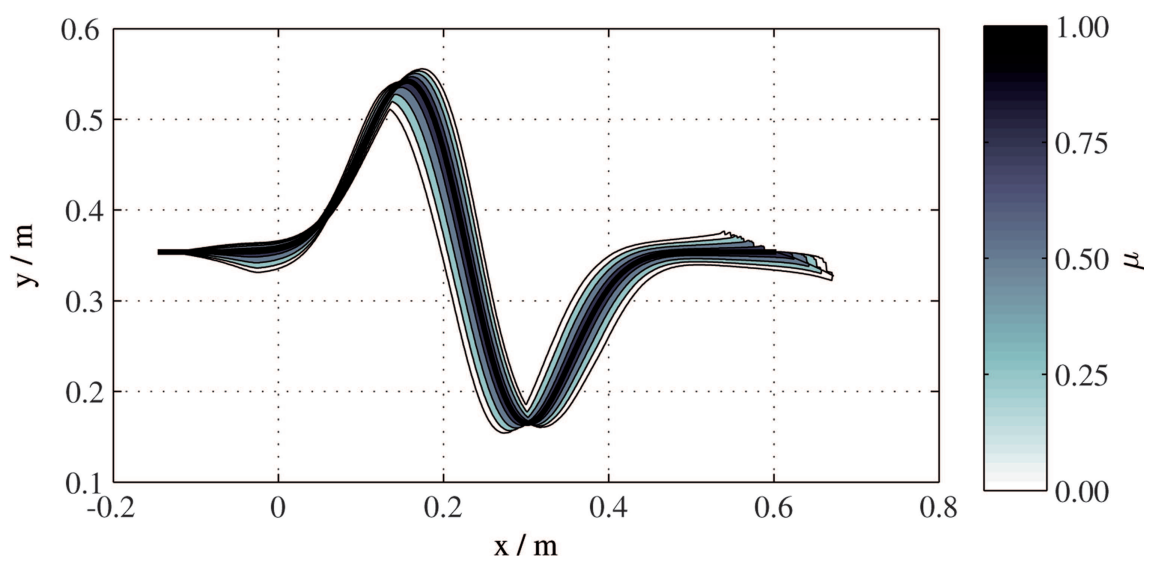

Fig. 3. Fuzzy solution of the end-effector motion of the feedforward system. The solution of the nominal system is displayed all black, the contour plot indicates the membership values of the possible solutions. The corresponding membership values $\mu$ are shown in the colorbar on the right-hand side
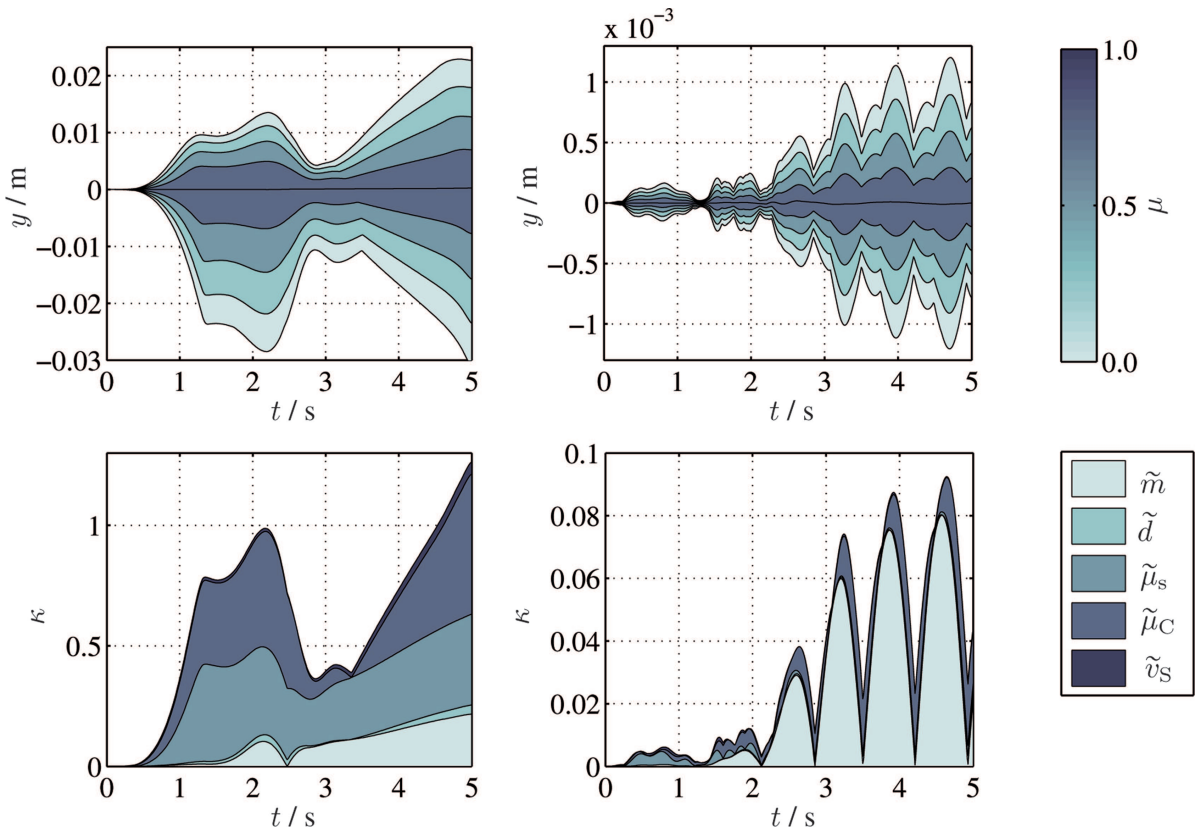

Fig. 4. Errors (top) and influence measures $\kappa_{i}$ (bottom) of the end-effector motion in $y$ direction of the open-loop (left) and closed-loop system (right). (Note the different scales.)

In order to account for the deviations caused by the imprecisely defined model parameters, one can apply some control, e.g. a PD-control

$$
T_{i}=-k_{\mathrm{p} i}\left(\theta_{\mathrm{ref}, i}-\theta_{i}\right)-k_{\mathrm{d} i}\left(\dot{\theta}_{\mathrm{ref}, i}-\dot{\theta}_{i}\right), \quad i \in\{1,2\},
$$

where the reference angles $\theta_{\text {ref }, i}$ and the angular velocities $\dot{\theta}_{\text {ref }, i}$ result from 
the definition of the reference trajectory, hence $\theta_{\mathrm{ref}, i}=\theta_{\mathrm{ref}, i}\left(x(t)_{\mathrm{ref}}, y(t)_{\mathrm{ref}}\right)$ and $\dot{\theta}_{\text {ref }, i}=\dot{\theta}_{\text {ref }, i}\left(x(t)_{\text {ref }}, y(t)_{\text {ref }}, \dot{x}(t)_{\text {ref }}, \dot{y}(t)_{\text {ref }}\right)$. For the sake of simplicity, the motor dynamics are not taken into account and the torques are used as control outputs directly.

Figure 4 shows errors (top) as well as the influence measures $\kappa_{i}$ (bottom) for the $y$-motion of the end effector of the open-loop (left) and closed-loop system (right). As illustrated, the overall uncertainty is reduced significantly by the controlller, which can be seen in both the error and the absolute influence. The influence of $d$ and $v_{\mathrm{S}}$ are negligible in both cases, and the significance of both damping and friction together is reduced in the closed-loop case because the friction moments take direct effect on the driving torques and are therefore well compensated by the PD-control. As a consequence, the remaining fuzziness of the output is primarily induced by the mass variation, where the major part stems from inertial effects which is obvious from the oscillatory behavior. The error bounds of the closed-loop system increase steadily for the lower membership levels, which indicates unstable behavior, while for $\mu \succsim \frac{3}{4}$, at least, the error stays bounded. Hence, the controller has only a rather small region of robustness with respect to model uncertainties. (Note that disturbances have not yet been taken into account.)

If desired, explicit margins of robustness, i.e. the maximum tolerable deviation of each model parameter from its nominal value, can easily be obtained by identifying the corresponding threshold value of the membership level $\mu$ for which stability is assured. In addition, using the supplementary information provided by the influence measures, it is possible to determine the parameters that are crucial in terms of robustness of the system and that should therefore be identified as accurate as possible. Since the influence measures can be calculated with respect to time, frequency or any other independent variable, the timespans or frequency ranges at which an identification of a model parameter can be accomplished more reliable are clearly assignable. This allows to neglect measurement data were no viable information for the identification is given. For example, the given output of the two-arm manipulator is not appropriate to estimate the value of the viscous damping factor $d$, the stiction coefficient $\mu_{\mathrm{s}}$, instead, shows a major influence over the whole timespan and thus is capable of being properly identified.

\section{Conclusion and Outlook}

Fuzzy arithmetic based on the Transformation Method has proven to be well suited to model, solve and analyze problems in multibody dynamics in the presence of uncertainties. Hereby, different designs can be rated with respect to their robustness against uncertainties, including the robustness as- 
sessments of controllers applied. Furthermore, the influence of each uncertain parameter individually can be quantified.

The Transformation Method is a generic procedure that is applicable to a wide range of problems, requiring only minor adjustments. Nevertheless, solving fuzzy-parameterized multibody systems goes along with some special requirements, where several open issues still have to be worked out some of which have been mentioned above. One of the limiting parts of computations involving uncertainties in complex systems is the increased computational effort. This effort is particularly connected to the number of uncertain parameters, since the computational complexity in general grows exponentially with the dimension of the parameter space for most of the available computational methods. For instance, in order to sample the edges of a hypercube, the number of sample points doubles with every dimension. This is also known as the curse of dimensionality. Therefore, methods for speeding up the calculations themselves, for instance by reducing the number of necessary model evaluations, are of vital interest. For the efficient computation of systems that contain uncertainties located in elastic bodies, pMOR methods have to be further investigated as well.

Manuscript received by Editorial Board, August 29, 2012;

final version, October 23, 2012.

\section{REFERENCES}

[1] Oberkampf W.L.: Model Validation under Both Aleatory and Epistemic Uncertainty. In Proc. of NATO AVT-147 Symposium on Computational Uncertainty in Military Vehicle Design, Athens, Greece, 2007.

[2] Zadeh L.A.: Fuzzy sets. Information and Control, Vol. 8, pp. 338-353, 1965.

[3] Hanss M.: The transformation method for the simulation and analysis of systems with uncertain parameters. Fuzzy Sets and Systems, Vol. 130, No. 3, pp. 277-289, 2002.

[4] Möller B., Beer M.: Fuzzy Randomness - Uncertainty in Civil Engineering and Computational Mechanics. Springer: Berlin, 2004.

[5] Schuëller G.I.: On the Treatment of Uncertainties in Structural Mechanics and Analysis. Computers and Structures, Vol. 85, No. 5-6, pp. 235-243, 2007.

[6] Augustin F., Gilg A., Paffrath M., Rentrop P., Wever U.: Polynomial chaos for the approximation of uncertainties: Chances and limits. European Journal of Applied Mathematics, Vol. 19, No. 2, pp. 149-190, 2008.

[7] Hemez F.M., Booker J.M., Langenbrunner J.R.: Answering The Question of Sufficiency: How Much Uncertainty is Enough?, In Proc. of The $1^{\text {st }}$ International Conference on Uncertainty in Structural Dynamics - USD 2007, Sheffield, UK, pp. 23-48, 2007.

[8] Kaufmann A., Gupta M.M.: Introduction to Fuzzy Arithmetic. Van Nostrand Reinhold: New York, 1991.

[9] Hanss M.: Applied Fuzzy Arithmetic - An Introduction with Engineering Applications. Springer: Berlin, 2005.

[10] Liu B.: A survey of credibility theory. Fuzzy Optimization and Decision Making, Vol. 5, No. 4, pp. 387-408, 2002. 
[11] Liu B.: Uncertainty Theory, 2nd ed., Springer: Berlin, 2007.

[12] Contreras H.: The stochastic finite-element method. Computers and Structures, Vol. 12, pp. 341-348, 1980.

[13] Handa K., Anderson K.: Application of finite element methods in the statistical analysis of structures. In Proc. of the 3rd Int. Conf. on Structural Safety and Reliability, pp. 409-417, 1981.

[14] Sandu A., Sandu C., Ahmadian M.: Modeling multibody systems with uncertainties. Part I: Theoretical and computational aspects. Multibody System Dynamics, Vol. 15, No. 4, pp. 369391, 2006.

[15] Batou A., Soize C.: Multibody system dynamics with uncertain rigid bodies. In Proceedings of the 8th International Conference on Structural Dynamics, EURODYN 2011, G. De Roeck, G. Degrande, G. Lombaert, G. Müller (eds.), pp. 2620-2625, 2011.

[16] Rao S.S., Sawyer J.P.: Fuzzy finite element approach for the analysis of imprecisely defined systems. AIAA Journal, Vol. 33, pp. 2364-2370, 1995.

[17] Moens D., Vandepitte D.: Fuzzy finite element method for frequency response function analysis of uncertain structures. AIAA Journal, Vol. 40, pp. 126-136, 2002.

[18] Wasfy T.M., Noor A.K.: Finite element analysis of flexible multibody systems with fuzzy parameters. Computer Methods in Applied Mechanics and Engineering, Vol. 160, No. 3-4, pp. 223-243, 1998.

[19] Dong W., Shah H.C.: Vertex method for computing functions of fuzzy variables. Fuzzy Sets and Systems, Vol. 24, No. 1, pp. 65-78, 1987.

[20] Berz M., Makino K.: Verified integration of ODEs and flows using differential algebraic methods on high-order Taylor models, Reliable Computing, 1998, Vol. 4, No. 4, pp. 361-369.

[21] Lin Y., Stadtherr M.A.: Validated solutions of initial value problems for parametric ODEs, Applied Numerical Mathematics, 2007, Vol. 57, No. 10, pp. 1145-1162.

[22] Klimke A., Willner K., Wohlmuth B.: Uncertainty modeling using fuzzy arithmetic based on sparse grids: applications to dynamic systems. International Journal of Uncertainty, Fuzziness and Knowledge-based Systems. Vol. 12, No. 6, pp. 745-759, 2004.

[23] Haag T., Reuß P., Turrin S., Hanss M.: An inverse model updating procedure for systems with epistemic uncertainties. In Proc. of the 2nd International Conference on Uncertainty in Structural Dynamics, Sheffield, UK, 2009.

[24] Haag T., Reuß P., Hanss M.: An Approach to the Identification of Uncertain Surrogate Models for Complex Systems. In. Proc. of the 19th Workshop Computational Intelligence, Dortmund, Germany, 2009.

[25] Haag T., Carvajal González S., Hanss M.: Model validation and selection based on inverse fuzzy arithmetic. Mechanical Systems and Signal Processing, 2011.

[26] Schiehlen W.: Research Trends in Multibody System Dynamics. Multibody System Dynamics, Vol. 18, No. 1, pp. 3-13, 2007.

[27] Kurz T., Eberhard P., Henninger C., Schiehlen W.: From Neweul to Neweul-M ${ }^{2}$ : Symbolical Equations of Motion for Multibody System Analysis and Synthesis. Multibody System Dynamics, Vol. 24, No. 1, pp. 25-41, 2010.

[28] Shabana A.A.: Dynamics of Multibody Systems Cambridge University Press, 2005.

[29] Shabana A.A.: Flexible Multibody Dynamics: Review of Past and Recent Developments. Multibody System Dynamics, Vol. 1, No. 2, pp. 189-222, 1997.

[30] Antoulas A.C., Sorensen D.C., Gugercin S.: A survey of model reduction methods for largescale systems. Contemporary mathematics, Vol. 280, pp. 193-220, 2001.

[31] Panzer H., Mohring J., Eid R., Lohmann B.: Parametric model order reduction by matrix interpolation at-Automatisierungstechnik, Vol. 58, No. 8, pp. 475-484, 2010.

[32] Baur U., Benner P.: Modellreduktion für parametrisierte Systeme durch balanciertes Abschneiden und Interpolation (Model Reduction for Parametric Systems Using Balanced Truncation and Interpolation) at-Automatisierungstechnik, Vol. 57, No. 8, pp. 411-419, 2009. 
Analiza systemów wieloczłonowych $\mathrm{z}$ niepewnościami wykorzystująca arytmetykę rozmytą

\section{Streszczenie}

Uwzględnienie niepewności w symulacji numerycznej jest generalnie rzeczą rozsądną. Podejście to często prowadzi do wiarygodnych rezultatów, toteż zyskuje na atrakcyjności w wielu dziedzinach technik symulacyjnych. Niemniej, w analizie systemów wieloczłonowych - inaczej niż w innych dziedzinach - niepewności były dotąd brane pod uwagę jedynie sporadycznie.

Termin "niepewność" jest często kojarzony z czynnikami o charakterze przypadkowym, tzn. niepewnościami aleatorycznymi, z którymi można z powodzeniem radzić sobie metodami teorii prawdopodobieństwa. W rzeczywistości, znaczna część niepewności występujących w systemach dynamicznych, a w szczególności w systemach wieloczłonowych, jest powiązana z tzw. niepewnościami epistemologicznymi, które obejmują m.in. niepewności spowodowane brakiem wiedzy, subiektywnością w implementacji modelu numerycznego, a także niepewności wynikające $\mathrm{z}$ uproszczeń i idealizacji. Tak więc, by modelować niepewności epistemologiczne w systemach wieloczłonowych wymagana jest odpowiednia teoria, która wciąż stanowi poważne wyzwanie. Na tym tle, autorzy przedstawiają metodologię, która pozwala na włączenie niepewności epistemologicznych w proces modelowania i analizy systemów wieloczłonowych. Prezentowane podejście jest oparte na arytmetyce rozmytej, specjalnej dziedzinie teorii zbiorów rozmytych, gdzie niepewne wartości parametrów modelu są reprezentowane przez tzw. liczby rozmyte, które odzwierciedlają, w sposób raczej intuicyjny lecz przekonywujący, nieostry zakres możliwych wartości parametrów. W rezultacie użycia tej zaawansowanej techniki modelowania uzyskuje się bardziej wszechstronny model systemu, który daje lepsze wyniki niż modele tradycyjne, o sztywnej parametryzacji. Wyniki symulacji, uzyskane przy zastosowaniu takiego modelu, odzwierciedlają zarówno dynamikę systemu, jak i efekty związane $\mathrm{z}$ niepewnościami.

Prezentowana metodologia jest zilustrowana przykładowym zastosowaniem do dynamiki systemu wieloczłonowego. Przykład pokazuje, że użycie zaawansowanych technik modelowania i symulacji, w których w sposób dobrze przemyślany uwzględniono prawdopodobne niepewności graniczne, może dostarczyć znacznych korzyści dodatkowych. 